\title{
Development of a disaster action plan for hospitals in Malaysia pertaining to critical engineering infrastructure risk analysis
}

\begin{abstract}
Critical engineering infrastructure (CEI) risk analysis is one of the tools used to measure potential risks in order to develop a disaster action plan (DAP). For hospitals, electricity and water supplies are two of the critical engineering infrastructures and when affected can become threats themselves. The objectives of this study are: i) to identify and analyse threats to water and electricity supplies, the threats being of high tendency to be realised during floods and socio-technical disasters; and ii) to review existing disaster action plans and subsequently develop a comprehensive one for water and electricity supplies and to be referred together with existing hospital DAPs. The HIRARC (Hazard Identification, Risk Assessment and Risk Control) guidelines provided by DOSH (Department of Occupation Safety and Health, Malaysia) were employed in the risk analysis process. This process was conducted through questionnaire surveys at several hospitals around Kota Bharu, Kuala Krai, Kajang, Serdang and Klang which have been hit by floods before. The survey involved 400 hospital and their concession company employees through interviews, meetings and workshop sessions. The development of the action plan followed the UNISDR guidance note on Emergency and Disaster Preparedness for Health Facilities and fulfilled the four phases of disaster management; mitigation, preparedness, response and recovery. Results of the analysis revealed that threats faced by the hospitals fall into four major categories; (i) submergence (ii) technical failure (iii) unpreparedness and (iv) unexpected events. The study also revealed that while the threats faced by Kota Bharu and Kuala Krai hospitals were of high risk those faced by Kajang, Serdang and Klang hospitals were mostly medium or low. Therefore, it is concluded that a comprehensive DAP based on the set objectives of ensuring continuous water and electricity supply and the enhancement of coordination among state health departments, hospital managements, concession companies and utility providers must be developed.
\end{abstract}

Keyword: Critical engineering infrastructure; Risk analysis; Disaster action plan 